\title{
İki farklı teknikle uygulanan üniversal bağlayıcı ajanların dentine olan makaslama bağlanma dayanımlarının incelenmesi
}

\author{
Elif Yaşa, ${ }^{1 *}$ Duygu Yıldızeli, ${ }^{2}$ Zübeyir Sayıner, ${ }^{2}$ \\ Ali Erdem ${ }^{1}$ \\ ${ }^{1}$ Serbest diş hekimi, Izmir, ${ }^{2}$ Serbest diş hekimi, İstanbul, \\ Türkiye
}

\section{Özet}

AmAÇ: Bu çalışmanın amacı, kendinden pürüzlendirmeli ve asitle-yıka teknikle uygulanan üniversal bağlayıcı ajanların dentine olan makaslama bağlanma dayanımlarını değerlendirmektir.

GeReÇ VE YönTEM: Çalışmamızda toplam 48 adet sağlam üçüncü büyük azı dişi kullanıldı. Oklüzal mine uzaklaştırıldıktan sonra açığa çıkan dentin yüzeyleri düzleştirildi. Dișler rastgele dört gruba ayrıldı ve elmas disk yardımıyla bukko-lingual yönde ikiye bölündü. Elde edilen yarımların her birine kendinden pürüzlendirmeli (a) veya asitle-yıka teknikle (b) All Bond Universal (Grup 1a ve 1b), Gluma Bond Universal (Grup $2 a$ ve $2 b$ ) veya Single Bond Universal (Grup 3a ve $3 b$ ) bağlayıcı sistemleri üretici firma talimatlarına göre uygulandı. Clearfil SE Bond (Grup 4a) kendinden pürüzlendirmeli ve Optibond FL (Grup 4b) asitle-yıka tekniğiyle kontrol grubu olarak kullanıldı. Örnekler nanohibrit kompozit rezin (Filtek Z550) kullanılarak restore edildi. Isıl yorma işleminden sonra örneklere üniversal test cihazında $0.5 \mathrm{~mm} / \mathrm{dk}$ hızla makaslama bağlanma testi uygulandı. Oluşan kırık tipleri stereomikroskop altında $\times \mathbf{4 0}$ büyütmede incelendi. Elde edilen veriler iki yönlü varyans analizi (ANOVA) ve Tukey çoklu karşılaştırma testi kullanılarak analiz edildi.

BULGULAR: Üniversal bağlayıcı sistemlerin makaslama bağlanma değerleri arasındaki farklılıklar istatistiksel olarak anlamlı bulundu $(p<0.05)$. Kendinden pürüzlendirmeli (a) gruplarında asitle-yıka (b) gruplarına göre anlamlı derecede daha yüksek bağlanma değerleri gözlendi $(p<0.05)$. Hem kendinden pürüzlendirmeli hem de asitleyıka teknikle uygulanan materyaller arasında Single Bond Universal en yüksek bağlanma dayanımını gösterirken en düşük bağlanma dayanımı All-Bond Universal grubunda gözlendi.

Makale gönderiliș tarihi: 06 Haziran 2016; Yayına kabul tarihi: 14 Ocak 2017 *iletişim: Elif Yaşa, Yeşilova Mah., 4016 Sokak, No: 9, Bornova, İmir, Türkiye; E-posta: dt.eliffiliz@ hotmail.com
Sonuç: Farklı tekniklerle uygulanan üniversal bağlayıcı sistemlerin dentine bağlanma dayanımları kullanılan materyale göre değişiklik gösterebilir. Asitle-yıka tekniğin kullanılması üniversal bağlayıcı ajanların dentine olan bağlanma dayanımını olumsuz etkilemektedir.

ANAHTAR Kelimeler: Asitle aşındırma, dental; bağlantı ajanları, dentin; kayma mukavemeti

KaynaK Göstermek İçin: Yaşa E, Yıldızeli D, Sayıner Z, Erdem A. İki farklı teknikle uygulanan üniversal bağlayıcı ajanların dentine olan makaslama bağlanma dayanımlarının incelenmesi Acta Odontol Turc 2017;34(3):91-7

ЕрітӧR: Neşe Akal, Gazi Üniversitesi, Ankara, Türkiye

YAYıN HAKKI: () 2017 Yaşa ve ark. Bu eserin yayın hakkı Creative Commons Attribution License ile ruhsatlandırılmıştır. Sınırsız kullanım, dağıtım ve her türlü ortamda çoğaltım, yazarlar ve kaynağın belirtilmesi kaydıyla serbesttir.

[Abstract in English is at the end of the manuscript]

\section{Giriş}

Günümüz diş hekimliğinde kompozit rezinler, geliştirilmiş fiziksel ve mekanik özellikleriyle doğala yakın estetik sağlanabilmesi ve minimal invaziv girişimle diş dokularına bağlanabilmesinden dolayı restoratif tedavide vazgeçilmez materyallerden birisi haline gelmiştir. Ancak kompozit rezinlerin diş dokularıyla mikro-mekanik bağlantı sağlayabilmesi bağlayıcı ajanların kullanımıyla gerçekleşmektedir. ${ }^{1,2}$

Bağlayıcı ajanlar klinik uygulama prosedürlerine göre üç ana kategoride sınıflandırılmaktadır. ${ }^{3}$ Birincisi üç aşamada veya iki aşamada uygulanabilen asitle-yıka (etch\&rinse) veya total-etch sistemidir. Üç aşamalı sistemlerde, fosforik asit uygulamasından sonra primer ve adeziv ayrı ayrı uygulanırken; iki aşamalı sistemlerde asit uygulamasının ardından tek bir şişede bulunan primer ve adeziv karışımı uygulanmaktadır., ${ }^{1,2} \mathrm{Bu}$ sistemlerde asidin ayrı bir basamak olarak uygulanması, dentin dokusunda smear tabakasının uzaklaşmasını ve kollagen fibrillerin ortaya çıkmasını sağlarken, minede yüzey alanının ve enerjisinin artmasına neden olmaktadır. ${ }^{2}$ Mineye bağlanmada herhangi bir teknik hassasiyet gerektirmeyen asitle-yıka sistemler, asidin uzaklaştırıl- 
masından sonra dentinin nemli bırakılması veya aşırı kurutulmasına bağlı olarak, adeziv sistemlerin bağlanma dayanımını önemli derece etkilemektedir. ${ }^{4}$ Dentinin nemli bırakılması, kollagenler arasında fazla suyun kalmasına, adeziv rezinin intertübüler alana penetre olamamasına ve ara yüzeyde demineralize bölgelerin kalmasına neden olmaktadır. ${ }^{5}$ Dentin aşırı kurutulduğunda ise kollajen fibriller çökmekte ve adeziv rezin bu boşlukları dolduramamaktadır. ${ }^{6}$ Sonuç olarak, her iki durumda da bağlanma olumsuz etkilenmektedir.5,6 Asitle-yıka sistemlerdeki bu nem sorununu çözmek için asit uygulaması gerektirmeyen teknik hassasiyeti daha düşük olan yeni bir bağlayıcı sistem geliştirilmiştir.

İkinci kategoride yer alan bu sistemler, kendinden pürüzlendirmeli ya da self-etch olarak adlandırılmaktadır. İki veya tek aşamada uygulanabilen bu sistemlerde asit ayrı bir basamak şeklinde uygulanmadığından smear tabakası tamamen kaldırılmazken, çözünen hidroksiapatit kristalleriyle birlikte hibrit tabakanın içerisinde yer almaktadır. ${ }^{2}$ Asidin uygulanmaması dentinin kurutulması sırasında neme karşı olan hassasiyetini ortadan kaldırırken, kullanılan asidin fosforik asit kadar kuvvetli olamaması da minenin yeterli derecede pürüzlendirilmesine engel olmaktadır. Bunun sonucunda da yapılan restorasyonlarda kenar kopmaları meydana gelmektedir. ${ }^{7}$ Mineyle olan bu bağlantı problemini çözmek için ise bu ajanların uygulamasından önce sadece mine kenarlarının asitlenmesi (selektif asitleme) önerilmiştir. Bu sefer de asidin yine ayrı bir basamak şeklinde uygulanması gerekmektedir. Ayrıca klinik şartlarda dentine taşırmadan sadece minenin asitlenmesi de pek mümkün olmamaktadır. ${ }^{2}$

Bütün bu uygulama aşamalarının karmaşıklığından dolayı, klinik uygulamayı basitleştirmek, çalışma zamanını kısaltmak, teknik hassasiyeti azaltmak için yeni bir bağlayıcı sistem daha geliştirilmiştir. ${ }^{8}$ Üniversal veya multi-mode bağlayıcı sistem olarak isimlendirilen bu ajanlar, asitle-yıka, kendinden pürüzlendirmeli veya selektif asitleme seçeneğiyle kullanılabilmektedir., ${ }^{1,2,9}$ Böylece klinikte hekime farklı durumlarda, tek bir bağlayıcı ajan ile, istediği sistemi seçme hakkı sunarak kullanım kolaylığı sağlamaktadır.

Bu çalışmanın amacı, hem kendinden pürüzlendirmeli hem asitle-yıka teknikle kullanılan üniversal bağlayıcı ajanların dentine olan makaslama bağlanma dayanımını değerlendirmektedir. Çalışmanın sıfır hipotezi, kendinden pürüzlendirmeli ve asitle-yıka teknikle uygulanan üniversal bağlayıcı ajanların dentine olan makaslama bağlanma dayanımları arasında fark olmadığıdır.

\section{Gereç Ve Yöntem}

Çalışmamızın etik kurul onayı Şifa Üniversitesi Klinik Araştırmalar Etik Kurulundan 353-92 numaralı referans numarasıyla alındı. Çalışmaya toplam 48 adet sağlam üçüncü büyük azı dişi dahil edildi. Üzerinde görünür çürük, çatlak, aşınma veya lekelenme olan dişler ise çalışma dışı bırakıldı. Dişıler üzerindeki tüm yumuşak ve sert eklentiler periodontal küret yardımıyla uzaklaştırılarak temizlendi ve deney başlangıcına kadar içine $1 \mathrm{mg} / \mathrm{L}$ timol kristali ilave edilen distile su içerisinde $37^{\circ} \mathrm{C}$ 'de saklandı.

Düz dentin yüzeyi oluşturmak için su soğutması altında dişlerin okluzal yüzeyleri disk şeklindeki elmas frez kullanılarak mine tamamen ortadan kaldırılıncaya kadar aşındırıldı. Hazırlanan örnekler her grupta 12 adet olacak şekilde rastgele 4 gruba ayrıldı. Bir grup kontrol grubu olarak kullanıldı. Daha sonra örnekler bukko-lingual yönde iki eşit parçaya ayrıldı ve dişlerin yüzeyleri yer düzlemine paralel olacak şekilde otopolimerizan akrilik rezinin (Duracryl Duradent, Bolzano, İtalya) içerisine yerleştirildi. Standart bir smear tabakası oluşturmak için dentin yüzeyleri, polisaj cihazında (Minitech 333, Presi, Eybens, Fransa) 60 sn süresince 600 grit silikon karbit zımparalar kullanılarak su soğutması altında aşındırıldı. Aşındırma işlemi sırasında oluşabilecek kişisel farklılıkları önlemek için uygulama işlemi tek bir kişi tarafından yapıldı. Bağlayıcı ajanlar, ikiye ayrılan örneklerden bir tanesine kendinden pürüzlendirmeli diğerine ise asitle-yıka teknik kullanılarak, üretici firma talimatlarına göre aşağıdaki gibi uygulandı:

Grup 1a; Single Bond Universal (kendinden pürüzlendirmeli; SBU-S): Single Bond Universal (3M ESPE, St. Paul, MN, ABD) dentin yüzeyine 20 sn süresince ovalanarak uygulandı, 5 sn hafif havayla kurutulduktan sonra 10 sn LED ışık cihazıyla (Demi Ultra, Kerr Corporation, Orange, CA, ABD) polimerize edildi.

Grup 1b; Single Bond Universal (asitle-yıka; SBU-T): Dentin yüzeyine 15 sn \%37' lik fosforik asit uygulandı. Asit hava-su spreyi ile tamamen yıkanıp, kurutuldu ve bağlayıcı ajan Grup 1a' da anlatıldığı şekilde uygulandı.

Grup 2a; All-Bond Universal (kendinden pürüzlendirmeli; ABU-S): All-Bond Universal (Bisco Inc., Schaumburg, IL, ABD) dentin yüzeyine 15 sn sürelerde ovalanarak iki tabaka şeklinde uygulandı, 10 sn hava ile kurutuldu ve LED ışık cihazı ile 10 sn ışıkla polimerize edildi.

Grup 2b; All-Bond Universal (asitle-yıka; ABU-T): Dentin yüzeyine 15 sn \%37 fosforik asit (Scotchbond Universal Etchant, 3M ESPE, St.Paul, MN, ABD) uygulandı. Asit hava-su spreyi ile tamamen yıkanıp, kurutuldu ve bağlayıcı ajan Grup 2a'da anlatıldığı şekilde uygulandı.

Grup 3a; Gluma Bond Universal (kendinden pürüzlendirmeli; GBU-S): Gluma Bond Universal (Heraeus Kulzer $\mathrm{GmbH}$, Hanau, Almanya) dentin yüzeyine $20 \mathrm{sn}$ süresince ovalanarak uygulandı ve 5 sn hafif havayla kurutulduktan sonra 10 sn LED ışık cihazıyla polimerize edildi.

Grup 3b; Gluma Bond Universal (asitle-yıka; GBU-T): Dentin yüzeyine 15 sn $\% 37$ fosforik asit uygulandı. Asit hava-su spreyi ile tamamen yıkanıp, kurutuldu ve bağlayıcı ajan Grup 3a'da anlatıldığı şekilde uygulandı. 
Grup 4a; Clearfil SE Bond (kendinden pürüzlendirmeli kontrol; SEB): Clearfil SE Bond'un (Kuraray Medical Inc., Okayama, Japonya) primeri dentin yüzeyine 20 sn uygulandı, 5 sn hava ile kurutulduktan sonra bond uygulanıp 10 sn LED ışık cihazıyla polimerize edildi.

Grup 4b; Optibond FL (asitle-yıka kontol; OFL): Dentin yüzeyine 15 sn \%37' lik fosforik asit uygulan-

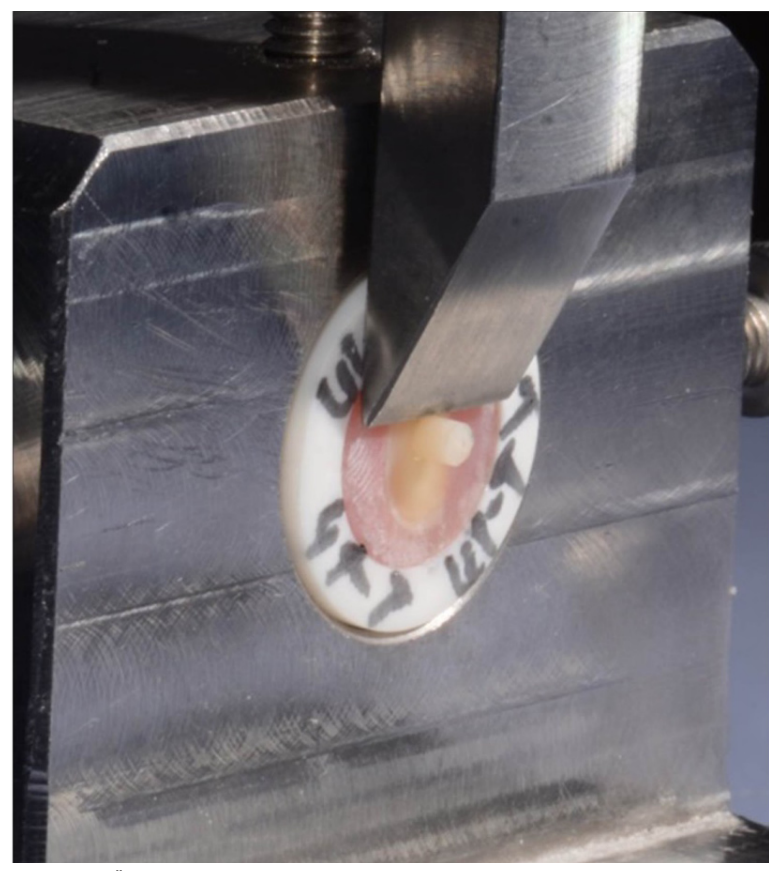

Resim 1. Örneklere makaslama bağlanma testinin uygulanması dı. Asit hava-su spreyi ile tamamen yıkanıp, kurutuldu. Optibond FL'nin (Kerr Corporation, Orange, CA, ABD) primeri dentin yüzeyine 15 sn uygulandı, 5 sn hafifçe hava ile kurutulduktan sonra bond dentin yüzeyine 15 sn süresince uygulanıp LED ışık cihazıyla polimerize edildi.

Çalışmada kullanılan tüm materyaller ve içerikleri Tablo 1'de verilmiştir. Adeziv sistemler üretici firmaların talimatları doğrultusunda uygulandıktan sonra diş yüzeyine $2.3 \mathrm{~mm}$ çapında ve $3 \mathrm{~mm}$ yüksekliğindeki plastik kalıplar (Ultradent Products Inc., South Jordan, UT, ABD) yerleştirilerek kompozit rezin (Z550, 3M ESPE) $2 \mathrm{~mm}$ tabakalar halinde uygulandı ve her tabaka $20 \mathrm{sn}$ ışıkla polimerize edildi. Daha sonra tüm örnekler polimerizasyonun tamamlanması için bir gün süreyle 37 ${ }^{\circ} \mathrm{C}$ 'de \%100 nemli ortamda bekletildi. Bu işlemi takiben tüm örnekler, ısıl yorma cihazında (Nova, Konya, Türkiye) $5-55^{\circ} \mathrm{C}$ aralığında $1000 \mathrm{kez}$ ısıl yorma işlemine tabi tutuldu.

Isıl yorma işleminden sonra örnekler, bağlantı yüzeyleri yer düzlemine dik olacak şekilde üniversal test cihazına (Autograph, Shimadzu, Tokyo, Japonya) yerleştirilerek, makaslama bağlanma dayanımı testi gerçekleştirildi. Makaslama bağlanma kuvvetinin saptanması amacıyla cihaza bağlı bıçak yüzeyli metal çubuk, diş ve materyalin birleşme bölgesine paralel şekilde konumlanarak, materyal dişten ayrılıncaya kadar $0.5 \mathrm{~mm} /$ dk hızla uygulandı (Resim 1). Tüm gruplara ait dentin yüzeylerindeki kompozit rezinlerin makaslama bağlanma değerleri Newton (N) cinsinden elde edildi ve yüzey alanına $\left(\mathrm{mm}^{2}\right)$ bölünerek MPa'ya çevrildi.

Tablo 1. Çalışmada kullanılan materyaller ve içerikleri

\begin{tabular}{|c|c|c|c|c|}
\hline Ürün & Materyal & Üretici firma & İçerik & Lot No \\
\hline $\begin{array}{l}\text { Scotchbond Universal } \\
\text { Etchant }\end{array}$ & Asit & $\begin{array}{l}\text { 3M ESPE, St. Paul, MN, } \\
\text { ABD }\end{array}$ & $\% 35$ fosforik asit & 582491 \\
\hline All-Bond Universal & $\begin{array}{l}\text { Universal } \\
\text { bağlayıcı ajan }\end{array}$ & $\begin{array}{l}\text { Bisco Inc., Schaumburg, } \\
\text { IL, ABD }\end{array}$ & MDP, Bis-GMA, HEMA, etanol, su, inisiyatörler & 14000004199 \\
\hline Gluma Bond Universal & $\begin{array}{l}\text { Universal } \\
\text { bağlayıcı ajan }\end{array}$ & $\begin{array}{l}\text { Heraeus Kulzer GmbH, } \\
\text { Hanau, Almanya }\end{array}$ & 4-Meta, metakrilat monomer, aseton, MDP & 010022 \\
\hline Single Bond Universal & $\begin{array}{l}\text { Universal } \\
\text { bağlayıcı ajan }\end{array}$ & $\begin{array}{l}\text { 3M ESPE, St. Paul, MN, } \\
\text { ABD }\end{array}$ & $\begin{array}{l}\text { MDP, fosfat monomer, dimetakrilat rezinler, HEMA, } \\
\text { metakrilat-modifiye polialkenoik asit kopolimeri, doldurucu, } \\
\text { etanol, su, inisiyatör, silan }\end{array}$ & 593550 \\
\hline Clearfil SE Bond & $\begin{array}{l}\text { Kendinden } \\
\text { pürüzlendirmeli } \\
\text { bağlayıcı ajan }\end{array}$ & $\begin{array}{l}\text { Kuraray Medical Inc., } \\
\text { Okayama, Japonya }\end{array}$ & $\begin{array}{l}\text { Primer: Su, MDP, HEMA, CQ, hidrofilik dimetakrilatlar } \\
\text { Adeziv: MDP,Bis-GMA, HEMA, CQ, } \\
\text { hidrofobik dimetakrilatlar, doldurucular }\end{array}$ & $\begin{array}{l}\text { Primer } \\
\text { A60170 } \\
\text { Adeziv } \\
\text { A50275 }\end{array}$ \\
\hline Optibond FL & $\begin{array}{l}\text { Asitle-yıka } \\
\text { bağlayıcı ajan }\end{array}$ & $\begin{array}{l}\text { Kerr Corporation, Orange, } \\
\text { CA, ABD }\end{array}$ & $\begin{array}{l}\text { Primer: HEMA, GPDM, MMEP, su, etanol, fotoinisiyatör } \\
\text { ve BHT } \\
\text { Adeziv: Bis-GMA, HEMA, GPDM, GDMA, CQ, } \\
\text { doldurucular }\end{array}$ & $\begin{array}{l}\text { Primer } \\
5592339 \\
\text { Adeziv } \\
5603319\end{array}$ \\
\hline Z550 & Kompozit rezin & $\begin{array}{l}\text { 3M ESPE, St. Paul, MN, } \\
\text { ABD }\end{array}$ & $\begin{array}{l}\text { Organik matriks: Bis-GMA, UDMA, Bis-EMA } \\
\text { İnorganik doldurucu: Zirconia/silika doldurucu (0.01-3.5 } \\
\mu \mathrm{m}, \% 82 \text { wt- } \% 60 \text { vol) }\end{array}$ & N677931 \\
\hline
\end{tabular}

MDP: metakriloloksidesil dihidrojen fosfat; Bis-GMA: bisfenol-A-glisidil dimetakrilat; HEMA: hidroksietil metakrilat; CQ: kanforokinon; GPDM: gliserofosforik asit dimetakrilat; MMEP: mono (2-metakriloyloksi) etil fitalat; GDMA: gliserol dimetakrilat; UDMA: üretan dimetakrilat, Bis-EMA: bisfenol A-dietoksi dimetakril 


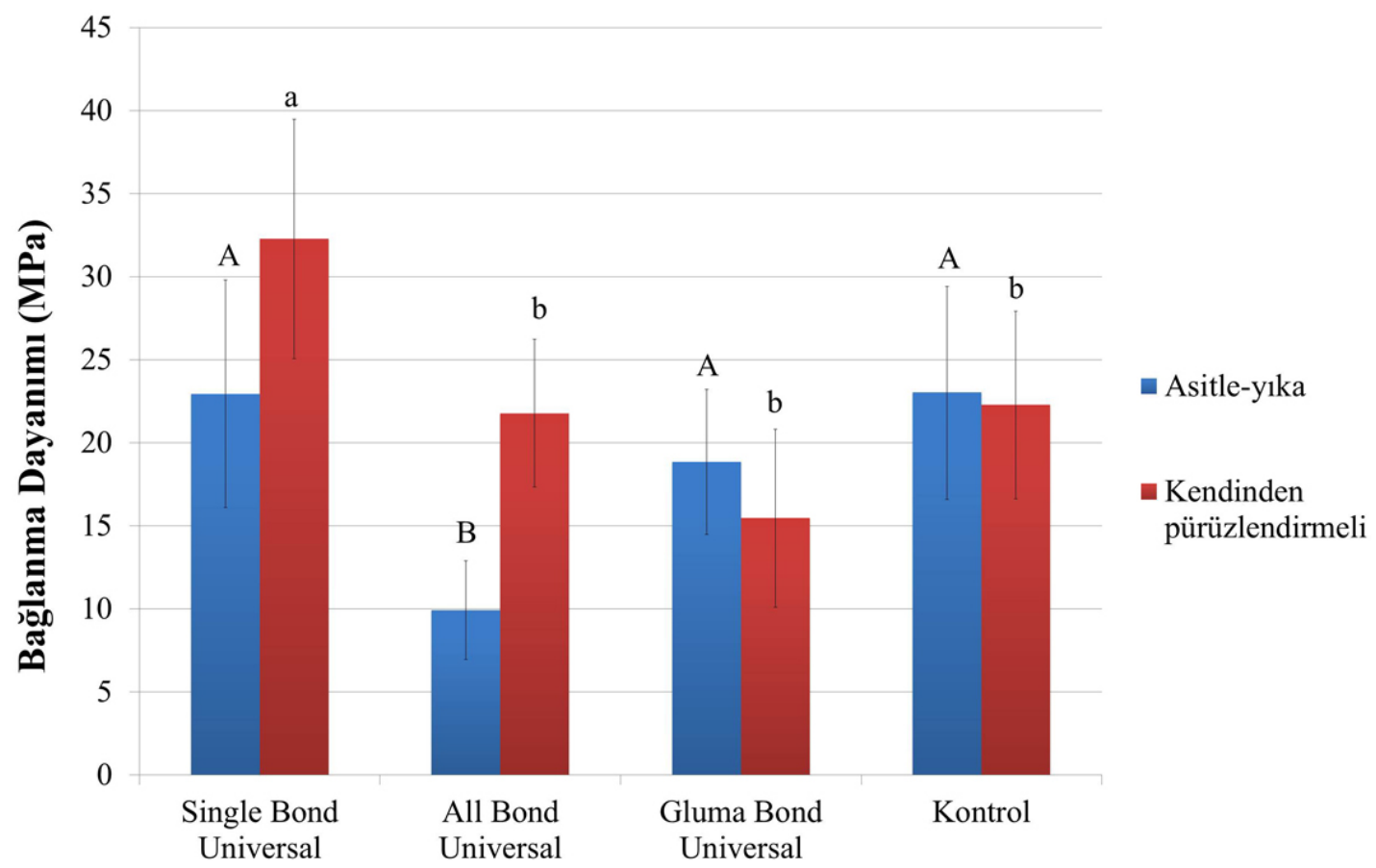

Şekil 1. Gruplara ait ortalama makaslama bağlanma dayanımı değerleri ve standart sapmaları şekilde görülmektedir. Asitle-yıka ve kendinden pürüzlendirmeli grupların grup içi farkları sırasıyla büyük ve küçük harflerle belirtilmiştir. Aynı simgeler istatistiksel olarak farklı olmayan grupları göstermektedir ( $p>0.05)$.

Örneklerin makaslama kuvvetleri sonucunda dentin-rezin bağlantı bölgesinde ortaya çıkan kırık tipleri ışık mikroskobunda (Primo Star, Zeiss, Goettingen, Almanya) $\times 40$ büyütmede değerlendirildi. Kırık tipleri adeziv, dentin içerisinde koheziv, kompozit rezin içerisinde koheziv ve adeziv/koheziv karışık tip şeklinde sınıflandırıldı. ${ }^{10}$

Çalışmamızın sonucunda elde ettiğimiz verilerin istatistiksel analizi SPSS (Version 20.0, SPSS Inc., Chicago, IL, ABD) yazılım programıyla gerçekleştirildi. Gruplar arasında fark olup olmadığını değerlendirmek için iki yönlü varyans analizi kullanıldı. Grupların ikili karşılaştırmaları Tukey post hoc testi kullanılarak gerçekleştirildi. Kırık tipleri arasındaki farklar ise $\chi^{2}$ testi ile belirlendi.

\section{BULGULAR}

Çalışmada kullanılan üniversal bağlayıcı ajanların iki faklı teknikle uygulanması sonucunda elde edilen ortalama makaslama bağlanma dayanımı değerleri (MPa) ve standart sapmaları Şekil 1'de verilmiştir.

İki yönlü varyans analizinin sonuçlarına göre makaslama bağlanma dayanımı değerleri arasındaki farklııklar istatistiksel olarak anlamlı bulundu $(p<0.05)$. Hem uygulanan materyal ve tekniğin hem de bunların etkileşiminin bağlanma dayanımı üzerindeki etkisinin an- lamlı olduğu görüldü. Tüm gruplar değerlendirildiğinde kendinden pürüzlendirmeli teknik asitle-yıka tekniğine göre daha yüksek bağlanma dayanımı değerleri gösterdi $(p<0.05)$. Uygulama tekniğine bakılmaksızın Single Bond Universal grubu en yüksek bağlanma dayanımını gösterirken en düşük bağlanma dayanımı All-Bond Universal grubunda gözlendi.

Kendinden pürüzlendirmeli teknikle uygulanan materyaller arasında en yüksek bağlanma dayanımı Single Bond Universal (32.29 $\pm 7.20 \mathrm{MPa})$ grubunda gözlendi ve diğer gruplarla arasındaki farklar istatistiksel olarak anlamlı bulundu $(p<0.05)$. Kontrol grubu $(22.29 \pm 5.64$ $\mathrm{MPa})$, All-Bond Universal (21.78 $\pm 4.45 \mathrm{MPa})$ ve Gluma Bond Universal (15.46 $\pm 5.35 \mathrm{MPa})$ ile karşılaştıııldığında daha yüksek bağlanma dayanımı değerleri göstermesine rağmen, aralarındaki farkın istatistiksel olarak anlamlı olmadığı görüldü ( $p>0.05)$.

Asitle-yıka teknikle uygulanan materyaller arasında da en yüksek bağlanma dayanımı kontrol grubunda $(23.03 \pm 6.41 \mathrm{MPa})$ gözlendi. Ancak kontrol grubunun Single Bond Universal $(22.95 \pm 6.85 \mathrm{MPa})$ ve Gluma Bond Universal $(18.85 \pm 4.36 \mathrm{MPa})$ gruplarıly arasındaki fark istatistiksel olarak anlamlı değildi $(p>0.05)$. All-Bond Universal $(9.93 \pm 2.98 \mathrm{MPa})$ ise tüm asitle-yıka grupları arasında istatistiksel olarak daha düşük değeri gösterdi $(p<0.05)$.

Örneklerin başarısızlık tipleri incelendiğinde grup- 
lar arasındaki farklar anlamsız bulundu. Genel olarak gruplarda adeziv tipte kırıkların olduğu; Single Bond Universal'in kendinden pürüzlendirmeli teknikle uygulandığı grupta ise dentinde daha fazla koheziv kırık tipi (\%42) olduğu görüldü (Şekil 2).

\section{TARTIŞMA}

Üniversal bağlayıcı ajanlar son yıllarda geliştirilen yeni jenerasyon adeziv sistemler olarak adlandırılmaktadır. Tek aşamalı kendinden pürüzlendirmeli adezivler gibi all-in-one konseptiyle geliştirilmelerine rağmen, klinik uygulamalarda farklı tekniklerle (asitle-yıka, kendinden pürüzlendirmeli) kullanımları mümkündür. ${ }^{11}$ Çalışmamızda, kendinden pürüzlendirmeli ve asitle-yıka teknikle uygulanabilen üç farklı üniversal bağlayıcı ajanın dentine olan makaslama bağlanma dayanımı değerlendirilmiş ve ajanlar kendinden pürüzlendirmeli teknikle uygulandıklarında ajanların daha yüksek bağlanma değerleri sergilediği görülmüştür. Bu nedenle çalışmanın sıfır hipotezi reddedilmiştir.

Kendinden pürüzlendirmeli adezivler dentini kısmen demineralize ederek, kollagen fibrillerin etrafında yeterli derecede hidroksilapatit kristalleri bırakırlar. ${ }^{12}$ Bağlayıcı ajanların içerisinde yer alan 10-metakriololoksidesil dihidrojen fosfat (MDP) monomerinin hidroksil apatit kristalleriyle kimyasal olarak bağlanabildiği ve bağlantı ara yüzeyinde mekanik dayanıklıığın daha da artmasını sağlayan bir nano tabakayı oluşturduğu bildirilmiştir. ${ }^{13}$ Buna ek olarak, nano tabaka boyunca stabil MDP-Ca tuzlarının birikmesi yüksek bağlanma dayanıklılığının oluşmasını sağlamaktadır. ${ }^{13,14}$ Çalışmamızda kullanılan üniversal bağlayıcı ajanların hepsinde ve kontrol grubu olarak kullanılan Clearfil SE Bond'un içerisinde de MDP bulunmaktadır. Kendinden pürüzlendirmeli teknikle uygulanan bu materyaller arasında en yüksek bağlanma dayanımı Single Bond Universal grubunda gözlemlenmiş ve aralarındaki fark istatistiksel olarak anlamlı bulunmuştur. Single Bond Universalin içerisinde MDP dışında, polialkenoik asit kopolimeri diğer bir ismiyle Vitrebond kopolimeri de bulunmaktadır. Bu kopolimerin içerisindeki karboksil gruplarının \%50'den fazlasının hidroksilapatit ile bağlandığı ve fosfat iyonlarıyla yer değişsirerek kalsiyum iyonlarıyla iyonik bağlar kurduğu belirtilmiştir. ${ }^{15} \mathrm{Bu}$ kimyasal etkileşim adeziv bağlanmayı olumlu etkilemektedir. ${ }^{16}$ Bundan dolayı SBU-S grubunun yüksek bağlanma değeri göstermesinin, MDP dışında polialkenoik asit kopolimeri de içermesiyle ilişkili olabileceği düşünülebilir. Her ne kadar çalışmamızda Single Bond Universal'in bağlanma dayanımı yüksek bulunsa da, literatürde çelişkili sonuçlar mevcuttur. Munoz ve ark. ${ }^{2}$ Clearfil SE Bond'un mikrogerilim bağlanma değerinin Single Bond Universal'den daha yüksek olduğunu bildirirken, Perdigao ve ark. ${ }^{17}$ Single Bond Universal'in dentin dokusuna Clearfil SE Bond'dan daha iyi bağlandığını bildirmişlerdir. Mevcut sonuçların birbirinden farklı olması, kullanılan dişlerin ve uygulanan yöntemlerin farklı olmasından kaynaklanabilmektedir.

Bağlayıcı ajanların içerisinde, MDP dışında fenil-P ve 4-META gibi fonksiyonel asidik monomerler de bulunabilmektedir. Yapılan çalışmalarda bu monomerlerden hiçbirisinin 10-MDP'den daha fazla bağlanma değeri göstermediği bildirilmiştir. ${ }^{18}$ Bunun nedeni olarak da monomerlerin oluşturduğu kalsiyum tuzlarının çö-

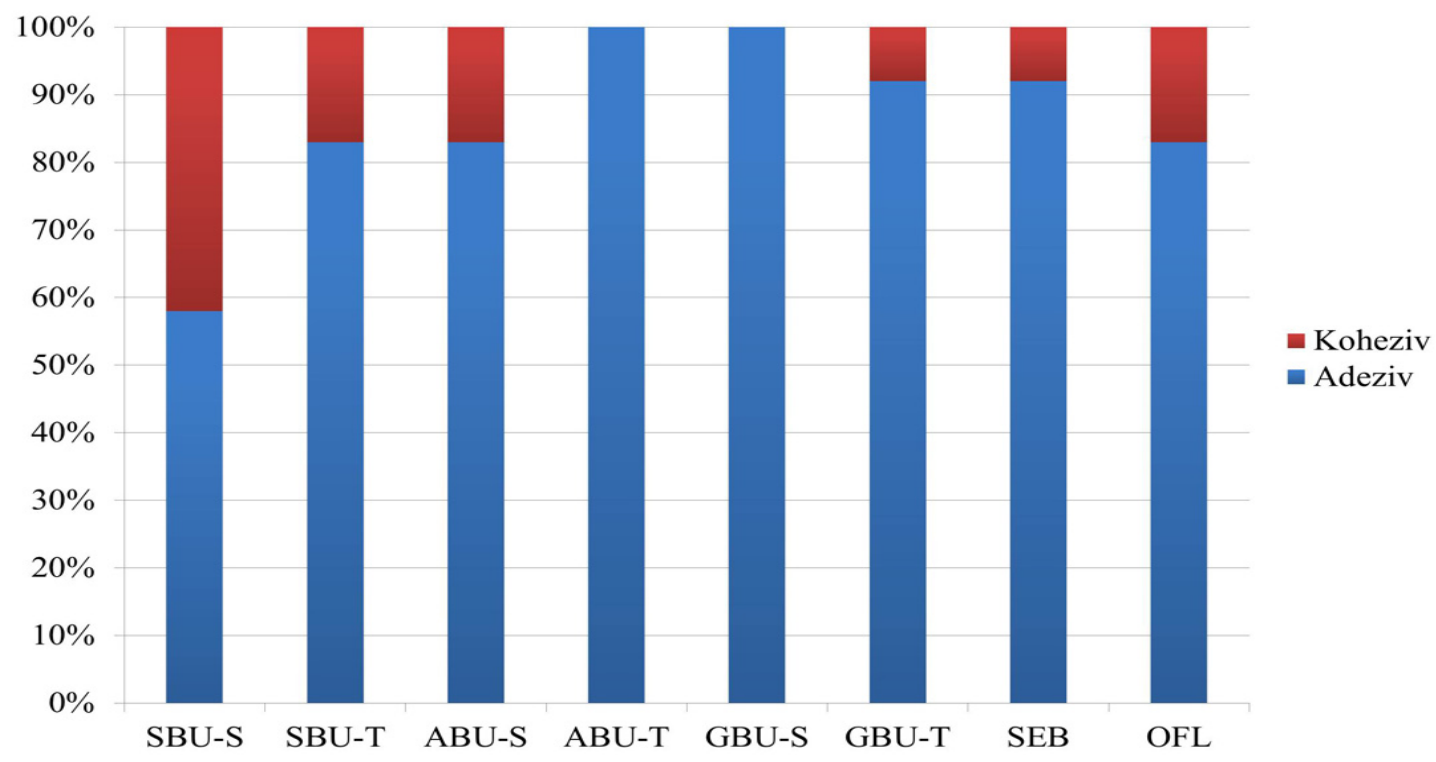

Şekil 2. Makaslama testi sonucu görülen kırık tiplerinin grup içi yüzdeleri şekilde görülmektedir. SBU-S: Single Bond Universal (kendinden pürüzlendirmeli); SBU-T: Single Bond Universal (asitle-yıka); ABU-S: All-Bond Universal (kendinden pürüzlendirmeli); ABU-T: All-Bond Universal (asitle-yıka); GBU-S: Gluma Bond Universal (kendinden pürüzlendirmeli); GBU-T: Gluma Bond Universal (asitle-yıka); SEB: Clearfil SE Bond (kendinden pürüzlendirmeli kontrol); OFL: Optibond FL (asitle-yıka kontrol) 
zünmeye karşı dayanıklı olamamaları ve hidrolitik bozulmaya uğramaları gösterilmiştir. Walter ve ark. ${ }^{19}$ farklı içeriğe sahip all-in-one bağlayıcı sistemlerdeki uzun yaşlandırma süresinin dentine olan bağlanma dayanımını değerlendirdikleri çalışmalarında, 4-META içerikli adezivlerin daha düşük bağlanma değerleri sergilediğini belirtmişlerdir. Çalışmamızda da kendinden pürüzlendirmeli gruplar arasında en düşük bağlanma dayanımı Gluma Bond Universal'de görülmüştür. Gluma Bond Universal'in içeriğinde 4-META bulunmasıyla birlikte, uygulanan termal değişimlerin monomeri bozulmaya uğratarak bağlantı değerlerini etkilediği düşünülebilir.

Kendinden pürüzlendirmeli bağlayıcı sistemler asiditelerine göre, güçlü $(\mathrm{pH}<1)$, orta derecede güçlü $(\mathrm{pH} 1.5)$, hafif $(\mathrm{pH} 2)$ ve ultra hafif $(\mathrm{pH} \geq 2.5)$ şeklinde sınıflandırılmaktadır. ${ }^{20}$ Çalışmada kullandığımız üniversal bağlayıcı ajanlardan sadece bir tanesi orta derecede güçlü asiditede [Gluma Bond Universal ( $\mathrm{pH} 1.6$ )] iken, diğerleri ultra hafif asiditeye [Single Bond Universal ( $\mathrm{pH}$ 2.8) ve All Bond Universal $(\mathrm{pH} 3.1)$ ] sahiptirler. Yapılan çalışmalarda, dentin tübüllerinde su bulunmasından dolayı güçlü kendinden pürüzlendirmeli bağlayıcı ajanlardaki bazı asidik monomerlerin asiditesini sürdürerek asitlemeyi devam ettirdiği belirtilmiştir.21,22 Bundan dolayı, polimerizasyonun tam olarak tamamlanamadığı ve yüksek asiditedeki kendinden pürüzlendirmeli bağlayıcı ajanların bağlanma dayanımını artırmadığı savunulmuştur. ${ }^{11,21,22}$ Çalışmamızda kendinden pürüzlendirmeli grupları arasında en düşük bağlanma dayanımını Gluma Bond Universal'in göstermesi bu bulguları destekler niteliktedir.

Kendinden pürüzlendirmeli bağlayıcı ajanlardan önce asit uygulanması, adezivin penetrasyon derinliğini artırarak, daha uzun rezin tagların ve daha kalın hibrit tabakasının oluşmasını sağlamaktadır. ${ }^{23,24}$ Ara yüzeyde artırımış bu yapısal kilitlenmeye rağmen, kendinden pürüzlendirmeli adezivler tek başına uygulandıklarında dentine daha yüksek bağlanma dayanımı göstermektedirler. Yapılan çalışmalarda hibrit tabakanın daha kalın ve rezin taglerin uzun olmasının, bağlanma dayanımını önemli derecede düşürdüğü bildirilmiştir. ${ }^{25,26}$ Düşük bağlanma dayanımının nedeni demineralize kollagen ağına bağlayıcı ajanın tam olarak infiltrasyonunu sağlayamamasıdır. ${ }^{27}$ Çalışmamızın bulgularına bakıldığında da asitle-yıka yöntemle uygulanan bağlayıcı ajanlar daha düşük bağlanma dayanımı göstermiştir.

Çalışmamızda kullanılan üniversal bağlayıcı ajanlardan All-Bond Universal asitle-yıka teknikle uygulandığında daha düşük bağlanma dayanımını sergilemiştir. Literatürde All-Bond Universal'in dentine olan bağlanma dayanımı için farklı sonuçlar mevcuttur. Munoz ve ark. ${ }^{2}$ All-Bond Universal'i kendinden pürüzlendirmeli ve asitle-yıka şeklinde uyguladıkları çalışmalarında bağlanma dayanımları arasında istatistiksel olarak anlamlı bir fark bulunmadığını bildirirken, bağlayıcı ajan kullanımından önce asit uygulamasının dentinde bağlanma dayanımını artırdığını bildiren çalışmalar da mevcuttur. ${ }^{28,29}$ Bunların aksine çalışmamızın bulgularına bakıldığında ise All Bond Universal kendinden pürüzlendirmeli teknikle uygulandığında dentinde daha yüksek bağlanma dayanımı göstermiştir. Yapılan çalışmalarda All Bond Universal'in ovalanarak uygulanmasının kendinden pürüzlendirmeli teknikle uygulandığında bağlanmayı artırabileceği rapor edilmiştir.2,11 Bu nedenle All Bond Universal'in kendinden pürüzlendirmeli teknikle uygulandığında dentinde daha yüksek bağlanma dayanımı göstermesini ovalanarak uygulanmasıyla ilişkili olabileceğini düşünmekteyiz.

Yapısal ve biyolojik olarak diş dokularının kişiden kişiye farklılık göstermesi, bağlayıcı ajan uygulamasıyla oluşan hibrit tabakanın yapısını etkilemektedir. ${ }^{30}$ Dişsel farklılıkları önleyebilmek için, çalışmamızda dişler bukko-lingual yönde ikiye bölünerek, bağlayıcı ajanların kendinden pürüzlendirmeli ve asitle-yıka uygulamaları tek bir diş üzerinde gerçekleştirilmiştir.

Çalışmamızdaki grupların kırık tipleri incelendiğinde bağlanma dayanımı ile kırık tipleri arasında belirli bir ilişki bulunmuştur. Bağlanma dayanımının yüksek olduğu gruplarda dentinde görülen koheziv kırık tipi daha fazlayken, bağlanma dayanımı düşük olan gruplarda ise adeziv kırık tipinin daha fazla olduğu bulunmuştur. Mevcut veriler daha önceki çalışmalarla uyumluluk içindedir. ${ }^{31,32}$

In vitro çalışmaların ağız içi koşulları tam olarak taklit edememesi gibi kısıtlamalar nedeniyle bu çalışmanın sonuçlarının desteklenebilmesi için üniversal bağlayıcı ajanların uzun dönem klinik performanslarının da değerlendirilmesi gerekmektedir.

\section{Sonuç}

Bu çalışmanın sınırları içerisinde, genel olarak üniversal bağlayıcı ajanların kendinden pürüzlendirmeli teknikle uygulanmasının dentine olan bağlanma dayanımlarını artırdığı gösterilmiştir. Ancak farklı tekniklerle uygulanan üniversal bağlayıcı sistemlerin dentin dokusuna olan bağlanma dayanımları kullanılan materyale göre değişiklik gösterebilmektedir.

Çıkar çatışması: Yazarlar bu çalışmayla ilgili herhangi bir çıkar çatışmalarının bulunmadığını bildirmişlerdir.

\section{KAYNAKLAR}

1. Thanaratikul B, Santiwong B, Harnirattisai C. Self-etch or etch-andrinse mode did not affect the microshear bond strength of a universal adhesive to primary dentin. Dent Mater J 2016;35:174-9.

2. Munoz MA, Luque I, Hass V, Reis A, Loguercio AD, Bombarda NH. Immediate bonding properties of universal adhesives to dentine. J Dent 2013;41:404-11.

3. De Munck JD, Van Landuyt K, Peumans M, Poitevin A, Lambrechts $\mathrm{P}$, Braem $\mathrm{M}$, et al. A critical review of the durability of adhesion to tooth tissue: methods and results. J Dent Res 2005;84:118-32.

4. Reis A, Pellizzaro A, Dal-Bianco K, Gomes O, Patzlaff R, Loguercio A. Impact of adhesive application to wet and dry dentin on long-term resin-dentin bond strengths. Oper Dent 2007;32:380-7.

5. Pioch T, Staehle HJ, Wurst M, Duschner H, Dörfer C. The nanoleakage phenomenon: influence of moist vs dry bonding. J Adhes Dent 2002;4:23-30. 
6. Hashimoto $\mathrm{M}$, Ohno $\mathrm{H}$, Kaga $\mathrm{M}$, Endo $\mathrm{K}$, Sano $\mathrm{H}$, Oguchi $\mathrm{H}$. In vivo degradation of resin-dentin bonds in humans over 1 to 3 years. J Dent Res 2000;79:1385-91.

7. Peumans M, De Munck J, Van Landuyt K, Poitevin A, Lambrechts $P$, Van Meerbeek B. Eight-year clinical evaluation of a 2-step selfetch adhesive with and without selective enamel etching. Dent Mater 2010;26:1176-84

8. Peumans M, Kanumilli $P$, De Munck J, Van Landuyt K, Lambrechts P, Van Meerbeek B. Clinical effectiveness of contemporary adhesives: a systematic review of current clinical trials. Dent Mater 2005;21:86481.

9. Hanabusa M, Mine A, Kuboki T, Momoi Y, Van Ende A, Van Meerbeek $B$, et al. Bonding effectiveness of a new 'multi-mode' adhesive to enamel and dentine. J Dent 2012;40:475-84.

10. Woronko GA Jr, St Germain HA Jr, Meiers JC. Effect of dentin primer on the shear bond strength between composite resin and enamel. Oper Dent 1996;21:116-21.

11. Wagner A, Wendler M, Petschelt A, Belli R, Lohbauer U. Bonding performance of universal adhesives in different etching modes. $J$ Dent 2014;42:800-7.

12. Tay FR, Pashley DH. Aggressiveness of contemporary self-etching systems: I: Depth of penetration beyond dentin smear layers. Dent Mater 2001;17:296-308

13. Yoshida $\mathrm{Y}$, Yoshihara K, Nagaoka N, Hayakawa S, Torii Y, Ogawa $\mathrm{T}$, et al. Self-assembled nano-layering at the adhesive interface. J Dent Res 2012;91:376-81.

14. Yoshihara K, Yoshida Y, Nagaoka N, Fukegawa D, Hayakawa S, Mine A, et al. Nano-controlled molecular interaction at adhesive interfaces for hard tissue reconstruction. Acta Biomater 2010;6:3573-82.

15. Barutçugil Ç, Kürklü $D$, Barutçugil $K$, Arslan $H$. Farklı yüzey işlemleri uygulanmış dentine üniversal bağlayıcı ajanın bağlanma dayanımının. Atatürk Üniv Diş Hek Fak Derg 2013;21:324-30.

16. Mena-Serrano A, Kose C, De Paula EA, Tay LY, Reis A, Loguercio $A D$, et al. A new universal simplified adhesive: 6-month clinical evaluation. J Esthet Restor Dent 2013;25:55-69.

17. Perdigao J, Sezinando A, Monteiro PC. Laboratory bonding ability of a multi-purpose dentin adhesive. Am J Dent 2012;25:153-8.

18. Yoshida $Y$, Nagakane K, Fukuda R, Nakayama $Y$, Okazaki M, Shintani $\mathrm{H}$, et al. Comparative study on adhesive performance of functional monomers. J Dent Res 2004;83:454-8.

19. Walter R, Swift EJ, Nagaoka H, Chung Y, Bartholomew W, Braswell $\mathrm{KM}$, et al. Two-year bond strengths of "all-in-one" adhesives to dentine. J Dent 2012;40:549-55

20. Van Meerbeek B, Yoshihara K, Yoshida Y, Mine A, De Munck J, Van Landuyt K. State of the art of self-etch adhesives. Dent Mater 2011;27:17-28.

21. Wang $Y$, Spencer $P$. Continuing etching of an all-in-one adhesive in wet dentin tubules. J Dent Res 2005;84:350-4.

22. Carvalho RM, Chersoni S, Frankenberger R, Pashley $\mathrm{DH}$, Prati C, Tay FR. A challenge to the conventional wisdom that simultaneous etching and resin infiltration always occurs in self-etch adhesives. Biomaterials 2005;26:1035-42.

23. Margvelashvili $M$, Goracci $C$, Beloica $M$, Papacchini $F$, Ferrari $M$. In vitro evaluation of bonding effectiveness to dentin of all-in-one adhesives. J Dent 2010;38:106-12.

24. Langer A, Ilie N. Dentin infiltration ability of different classes of adhesive systems. Clin Oral Investig 2013;17:205-16.

25. Ikeda M, Tsubota K, Takamizawa T, Yoshida T, Miyazaki M, Platt J. Bonding durability of single-step adhesives to previously acid-etched dentin. Oper Dent 2008;33:702-9.

26. Van Landuyt K, Kanumilli $P$, De Munck J, Peumans M, Lambrechts $P$, Van Meerbeek B. Bond strength of a mild self-etch adhesive with and without prior acid-etching. J Dent 2006;34:77-85.

27. Hashimoto M, Ohno H, Endo K, Kaga M, Sano H, Oguchi H. The effect of hybrid layer thickness on bond strength: demineralized dentin zone of the hybrid layer. Dent Mater 2000;16:406-11.
28. Rosa WL, Piva E, Silva AF. Bond strength of universal adhesives: A systematic review and meta-analysis. J Dent 2015;43:765-76.

29. Lee IS, Son S, Hur B, Kwon YH, Park JK. The effect of additional etching and curing mechanism of composite resin on the dentin bond strength. J Adv Prosthodont 2013;5:479-84.

30. Sancaklı HŞ. Dentin bağlayıcı sistemler ve hibrid tabakanın oluşturulması. J Istanbul Uni Fac Dent 2010;44:189-95.

31. Pleffken PR, de Almeida Lourenco AP, Torres C, Buhler Borges A. Influence of application methods of self-etching adhesive systems on adhesive bond strength to dentin. J Adhes Dent 2011;13:517-25

32. Amano S, Yamamoto A, Tsubota K, Rikuta A, Miyazaki M, Platt J, et al. Effect of thermal cycling on enamel bond strength of single-step self-etch systems. Oper Dent 2006;31:616-22.

\section{Investigation of the shear bond strength to dentin of universal adhesives applied with two different techniques}

\begin{abstract}
OBJECtIVE: The aim of this study was to evaluate the shear bond strength of universal adhesives applied with selfetch and etch\&rinse techniques to dentin.
\end{abstract}

Materials AND Method: Forty-eight sound extracted human third molars were used in this study. Occlusal enamel was removed in order to expose the dentinal surface, and the surface was flattened. Specimens were randomly divided into four groups and were sectioned vestibulo-lingually using a diamond disc. The universal adhesives: All Bond Universal (Group 1a and 1b), Gluma Bond Universal (Group 2a and 2b) and Single Bond Universal (Group 3a and $3 \mathrm{~b}$ ) were applied onto the tooth specimens either with self-etch technique (a) or with etch\&rinse technique (b) according to the manufacturers' instructions. Clearfil SE Bond (Group 4a; self-etch) and Optibond FL (Group 4b; etch\&rinse) were used as control groups. Then the specimens were restored with a nanohybrid composite resin (Filtek Z550). After thermocycling, shear bond strength test was performed with a universal test machine at a crosshead speed of $0.5 \mathrm{~mm} / \mathrm{min}$. Fracture analysis was done under a stereomicroscope ( $\times 40$ magnification). Data were analyzed using two-way ANOVA and post-hoc Tukey tests.

RESULTS: Statistical analysis showed significant differences in shear bond strength values between the universal adhesives $(p<0.05)$. Significantly higher bond strength values were observed in self-etch groups (a) in comparison to etch\&rinse groups $(b)(p<0.05)$. Among all groups, Single Bond Universal showed the greatest shear bond strength values, whereas All Bond Universal showed the lowest shear bond strength values with both application techniques.

ConCLUSION: Dentin bonding strengths of universal adhesives applied with different techniques may vary depending on the adhesive material. For the universal bonding agents tested in this study, the etch\&rinse technique negatively affected the bond strength to dentin.

KEYWORDS: Acid etching, dental; bonding agents, dentin; shear strength 